\title{
Goblet Cells and Mucin Related Gene Expression in Mice Infected with Eimeria papillata
}

\author{
Mohamed A. Dkhil, ${ }^{1,2}$ Denis Delic, ${ }^{3}$ and Saleh Al-Quraishy ${ }^{1}$ \\ ${ }^{1}$ Department of Zoology, College of Science, King Saud University, P.O. Box 2455, Riyadh 11451, Saudi Arabia \\ ${ }^{2}$ Department of Zoology and Entomology, Faculty of Science, Helwan University, Cairo, Egypt \\ ${ }^{3}$ Department of Molecular Parasitology, Heinrich Heine University, Duesseldorf, Germany
}

Correspondence should be addressed to Mohamed A. Dkhil; mohameddkhil@yahoo.com

Received 30 September 2013; Accepted 12 November 2013

Academic Editors: G. Cancrini and Á. Criado-Fornelio

Copyright (C) 2013 Mohamed A. Dkhil et al. This is an open access article distributed under the Creative Commons Attribution License, which permits unrestricted use, distribution, and reproduction in any medium, provided the original work is properly cited.

Coccidiosis causes considerable economic loss in the poultry industry. The current study aimed to investigate the response of goblet cells as well as the induced tissue damage during Eimeria papillata infection. Mice were infected with sporulated E. papillata oocytes. On day 5 postinfection, the fecal output was determined. Also, the jejunum was prepared for the histological, histochemical, and molecular studies. Our results revealed that the intestinal coccidian infection with E. papillata induced a marked goblet cell hypoplasia and depleted mucus secretion. Also, the infection was able to alter the jejunal architecture and increased the apoptotic cells inside the villi. In addition, the real-time PCR results indicated that the inflammatory cytokines: TNF- $\alpha$, iNOS, IFN- $\gamma$, and IL-1 $\beta$, were significantly upregulated. In contrast, the mRNA expression patterns of IL-6 in response to E. papillata infection did not differ significantly between control and infected mice. Moreover, the mRNA expression of TLR4 was significantly upregulated, whereas the expression of MUC2 is significantly downregulated upon infection. Further studies are required to understand the regulatory mechanisms of goblet cells related genes.

\section{Introduction}

The intestine plays an important role in the digestion and absorption of ingested food and the elimination of undigested food, microbes, and microbial products [1]. The mucus layer coating the gastrointestinal tract is the front line of innate host defense, largely because of the secretory products of intestinal goblet cells [2].

Intestinal goblet cells are highly polarized secretory cells that are present throughout the intestinal tract. These specialized epithelial cells are thought to play an important protective role in the intestine by synthesizing and secreting several mediators, including the mucin MUC2 [3].

Indeed, infection with Eimeria parasites has been associated with increase in the incidence of the pathological conditions in poultry [4]. These parasites cause various problems ranging from gastroenteritis, anorexia, abdominal distention, diarrhoea, emaciation, and so forth, all of which result in serious economic losses to the farmer as well as the nation in general [4]. Since coccidioses lead to a significant impact on the livestock industry, we characterized the goblet cells response in mice inoculated with Eimeria papillata that infects enterocytes of the jejunum and shares many biological characteristics with the important pathogen of chickens, $E$. tenella [5].

The present study aimed to investigate the goblet cell response and its correlated genes during the infection with E. papillata in mice.

\section{Materials and Methods}

2.1. Animals. Twenty adult male Swiss albino mice weighing 35-30 $\mathrm{g}$ and aged 9-12 weeks were obtained from the animal facilities of King Saud University, Riyadh, Saudi Arabia. The mice were bred under specified pathogen-free conditions and fed a standard diet and water ad libitum. The experiments were approved by state authorities and followed Saudi Arabian rules for animal protection. 


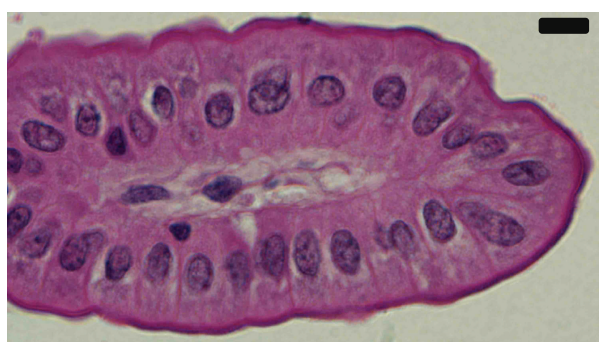

(a)

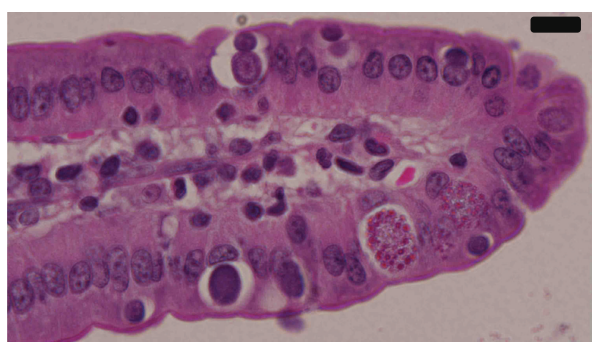

(b)

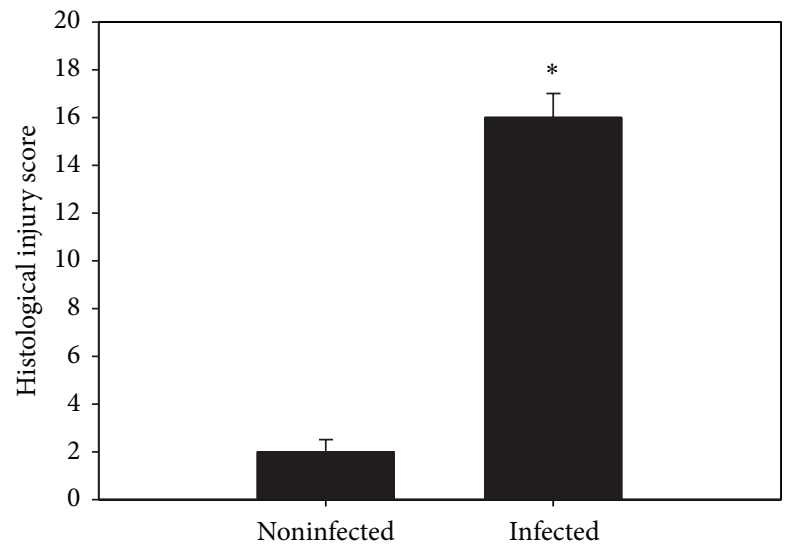

(c)

Figure 1: E. papillata-induced jejunum injury on day 5. (a) Noninfected jejunum with normal architecture of the absorptive epithelium and lamina propria. (b) Infected jejunum with some pathological changes in lamina propria and absorptive epithelia. Developmental stages appearing in the absorptive epithelia. Sections are stained with hematoxylin and eosin. Bar $=25 \mu \mathrm{m}$. (c) Total histological injury score in jejunum of mice infected with E. papillata on day 5 p.i. Values are means \pm SD. ${ }^{*}$ Significant at $P \leq 0.05 . n=10$.

2.2. Experimental Design. Two groups of mice, with 10 animals per group, were investigated. The first group was inoculated only with sterile saline and served as the control group. The second group was orally infected with $10^{3}$ sporulated oocysts of E. papillata.

2.3. Infection of Mice. A self-healing strain of E. papillata was kindly provided by Professor Mehlhorn (Heinrich Heine University, Duesseldorf, Germany). Infected mice were orally inoculated with 1000 sporulated oocysts of E. papillata suspended in $100 \mu \mathrm{L}$ sterile saline. Subsequently, fresh faecal pellets were collected every $24 \mathrm{~h}$. The collected pellets from each mouse were weighed and the bedding was changed to eliminate reinfection. Oocyst output was measured as previously described [6]. Faecal pellets were suspended in $2.5 \%$ (wt/vol) potassium dichromate and diluted in saturated sodium chloride for oocyst flotation. Oocysts were counted in a McMaster chamber and expressed as number of oocysts per gram of wet faeces.

2.4. Histological Analysis. Pieces of jejunum were freshly prepared from mice on day 5 postinfection with E. papillata, fixed in $10 \%$ neutral buffered formalin, and then embedded in paraffin. Sections were cut and then stained with hematoxylin and eosin. According to Dommels et al. [7], tissue sections were scored for inflammatory lesions (infiltrations by mononuclear cells, neutrophils, eosinophils, and plasmacytes, for fibrin exudation and lymphangiectasis), for tissue destruction (enterocyte loss, ballooning degeneration, edema, and mucosal atrophy), and for tissue repair (hyperplasia, angiogenesis, granulomas, and fibrosis). A rating score between 0 (no change from normal tissue) and 3 (lesions involved most areas and all the layers of the intestinal section including mucosa, muscle, and omental fat) was given for each aspect of inflammatory lesions, tissue destruction, and tissue repair. The sum of inflammatory lesions, tissue destruction, and tissue repair scores was used to represent the total histological injury score (HIS) for each intestinal section. The sum of the inflammatory lesions was multiplied by 2 to give more weight to this value since the tissue changes were mainly characterized by inflammatory lesions [7].

2.5. TUNEL Apoptosis Detection. Jejunum was collected on day 5 postinfection and terminal deoxynucleotidyl transferase mediated dUTP nick end labeling (TUNEL) assay staining was performed using a TUNEL Apoptosis Detection Kit (GenScript, Piscataway, NJ, USA) by following the manufacturer's protocol. Briefly, sections of paraffin-embedded jejunum were deparaffinized, rehydrated in gradient ethanol, and then digested with proteinase $\mathrm{K}$. Slides were mounted with $4^{\prime}, 6$-diamidino-2-phenylindole (DAPI). Using this procedure, positive nuclei of apoptotic cells are stained dark brown. Sections were counterstained with hematoxyline. For each animal, the number of apoptotic cells in the jejunum 


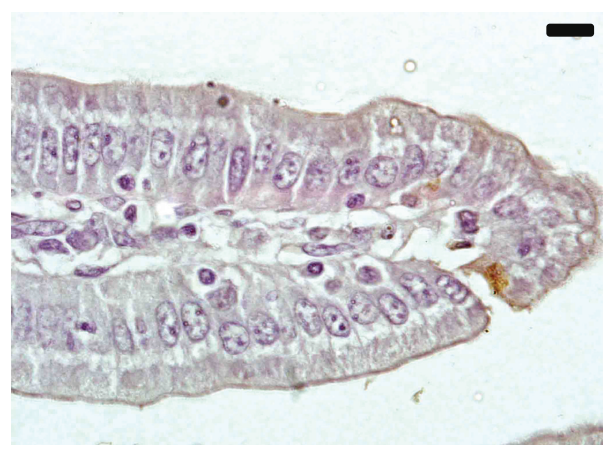

(a)

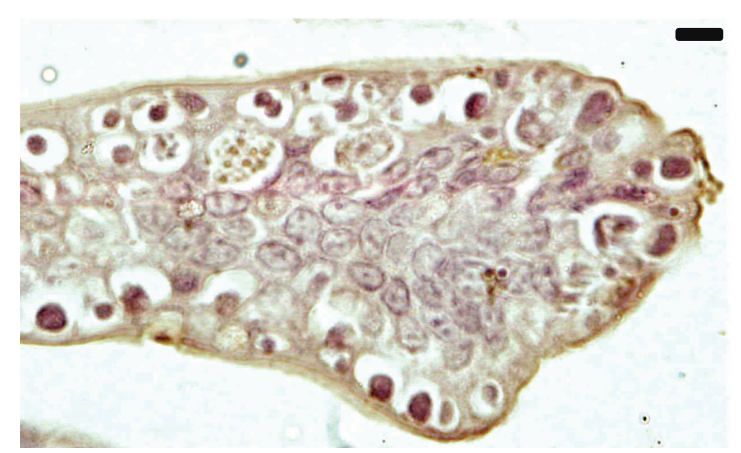

(b)

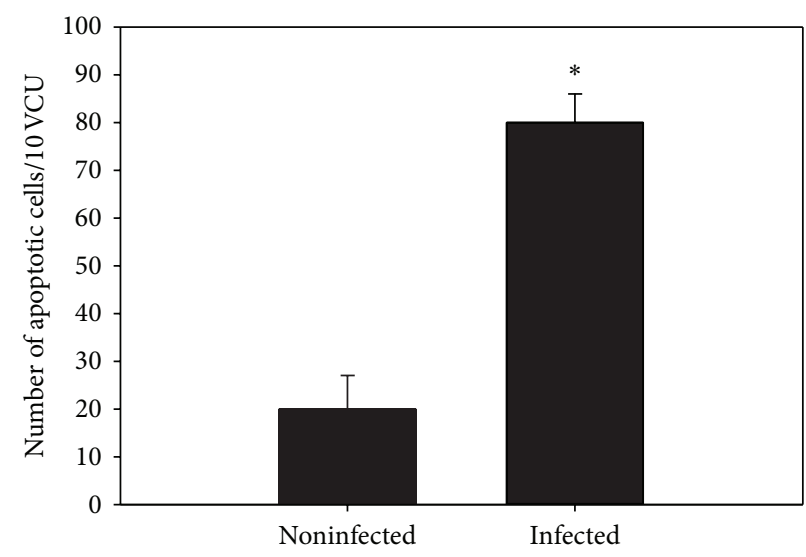

(c)

FIGURE 2: Changes in apoptotic cells in mouse jejunum infected with E. papillata. (a) Noninfected jejunum (b) Infected jejunum with increased number of TUNEL-positive cells in lamina propria. Bar $=25 \mu \mathrm{m}$. (c) Infection-induced changes in apoptotic cells number in jejunal crypts. Values are means $\pm \mathrm{SD}$. *Significant at $P \leq 0.05 . n=10$.

was counted on at least ten well-orientated villous-crypt units (VCU). Results were expressed as the mean number of apoptotic cells per ten VCU.

2.6. The Number of Goblet Cells. Sections were stained with Alcian blue for determination of the goblet cells. For each animal, the number of goblet cells in the jejunum was counted on at least ten well-orientated villous-crypt units (VCU). Results were expressed as the mean number of goblet cells per ten VCU [8].

2.7. Quantitative Real-Time PCR. Pieces of jejunum were aseptically removed, rapidly frozen, and stored in liquid nitrogen until use. Total RNA was isolated using Trizol (Invitrogen). RNA samples were treated with DNase (Applied Biosystems, Darmstadt, Germany) for at least $1 \mathrm{~h}$ and were then converted into cDNA by following the manufacturer's protocol using the reverse transcription kit (Qiagen, Hilden, Germany). Quantitative real-time PCR (qRT-PCR) was performed using the ABI Prism 7500HT sequence detection system (Applied Biosystems, Darmstadt, Germany) with SYBR green PCR master mix from Qiagen (Hilden, Germany). We investigated the genes encoding the mRNAs for the following proteins: interleukin-1 $\beta$ (IL-1 $\beta$ ), interleukin-6 (IL-6), tumor necrosis factor alpha (TNF- $\alpha)$, interferon- $\gamma(\operatorname{IFN} \gamma)$, toll-like receptor 4 (TLR4), inducible nitric oxide synthase (iNOS), and mucin 2 (MUC2). All primer assays used for qRTPCR were obtained commercially from Qiagen. PCRs were performed as follows: $2 \mathrm{~min}$ at $50^{\circ} \mathrm{C}$ to activate uracil- $N$ glycosylase (UNG); $95^{\circ} \mathrm{C}$ for $10 \mathrm{~min}$ to deactivate $\mathrm{UNG}$; and 40 cycles at $94^{\circ} \mathrm{C}$ for $15 \mathrm{~s}, 60^{\circ} \mathrm{C}$ for $35 \mathrm{~s}$, and $72^{\circ} \mathrm{C}$ for $30 \mathrm{~s}$. Reaction specificity was checked by performing dissociation curves after PCR. mRNA levels were normalized to 18S rRNA. The fold induction of mRNA expression upon infection with E. papillata was determined using the $2-\Delta \Delta \mathrm{CT}$ method [9].

2.8. Statistical Analysis. A two-tailed Student $t$-test was used for statistical analysis.

\section{Results}

The course of E. papillata infections in mice was recently characterized in detail $[10,11]$. The number of excreted oocysts varied among the individual mice between 200,000 and 260,000 per gram feces (mean value, 235, $000 \pm 24,000$ ).

Light microscopical inspection of hematoxylin-andeosin-stained sections revealed that the epithelial cells of the jejunum were infected by E. papillata. Concomitantly, there occurred some histological changes which were semiquantified by applying the scoring according to Dommels 


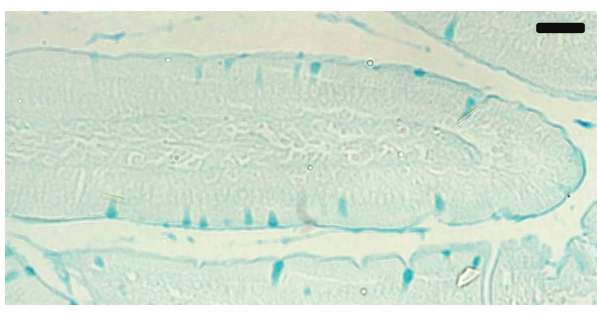

(a)

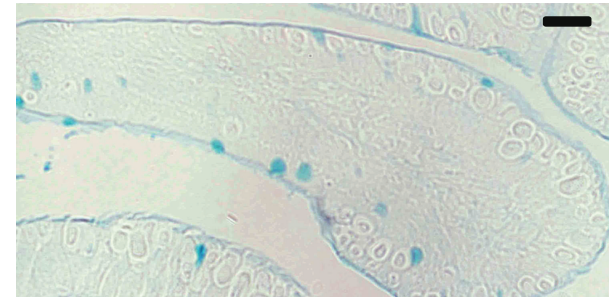

(b)

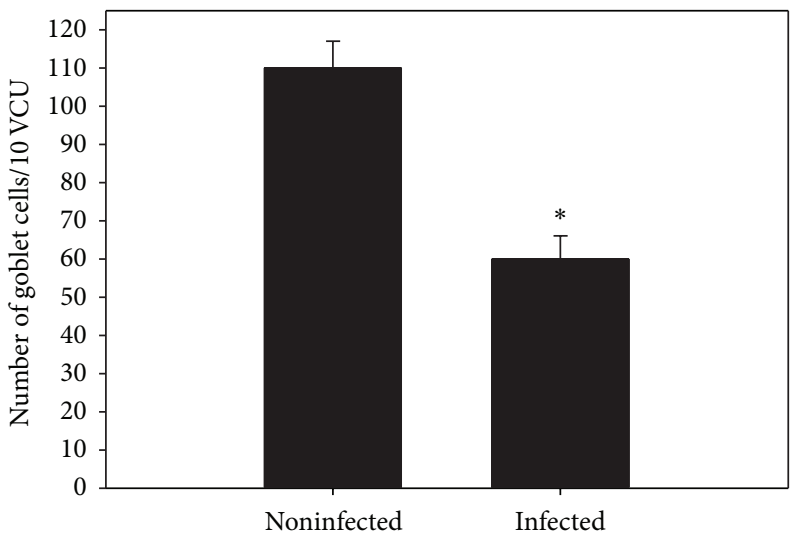

(c)

FIGURE 3: Changes in goblet cell numbers in mouse jejunum infected with E. papillata. (a) Noninfected jejunum with more goblet cells. (b) Non-infected treated mouse jejunum. Sections are stained with Alcian blue. Bar $=25 \mu \mathrm{m}$. (c) Number of goblet cells in jejunum of mice at day 5 p.i. Values are means \pm SD. ${ }^{*}$ Significant at $P \leq 0.05 . n=10$.

et al. [7]. Histological analysis revealed that mice infected with sporulated oocysts of E. papillata suffered a moderate inflammatory injury in jejunum (Figure 1).

Infection of mice with E. papillata induced a significant increase in the number of TUNEL-positive cells of the jejunal crypts compared to the noninfected controls (Figure 2). In addition, there was a significant reduction of the goblet cell numbers seen at the site of the E. papillata infection in the jejunum (Figure 3).

Quantitative real-time PCR was used to detect changes in the mRNA levels of inflammatory and goblet cell associated genes in the intestine. Upon infection with E. papillata, there was a significant increase in the mRNA expression of TNF- $\alpha$, iNOS, IFN- $\gamma$, and IL- $1 \beta$. In contrast, the mRNA expression patterns of IL-6 in response to E. papillata infection did not differ significantly between control and infected mice (Figure 4). The mRNA expression of TLR4 is significantly upregulated, whereas the expression of MUC2 is significantly downregulated upon infection (Figure 5).

\section{Discussion}

Intestinal infection with E. papillata can induce substantial pathological changes in the epithelial compartment [11], as leads to a dramatic reduction in the number of goblet cells [11]. The mucus released by goblet cells can function as a defensive barrier $[12,13]$. Our results demonstrated that goblet cells were most evident in the infected crypt and much less so in the neighboring and other uninfected areas of

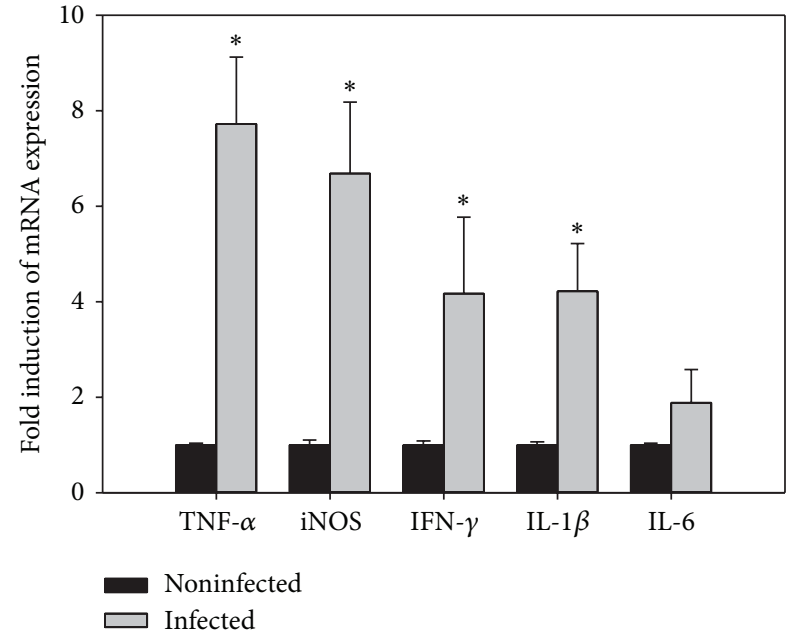

FIGURE 4: Quantitative RT-PCR analysis of TNF- $\alpha$, iNOS, IFN- $\gamma$, IL$1 \beta$ and IL- 6 in the jejunum. Expression was analyzed in noninfected and infected mice on day 5 p.i., normalized to $18 \mathrm{~S}$ rRNA signals, and relative expression is given as fold increase compared to the noninfected control mice. Values are means $\pm \mathrm{SD}$. ${ }^{*}$ Significant change at $P<0.01$ with respect to non-infected mice.

the intestine. In addition, the parasites were mostly discovered at the bottom of the intracrypt epithelium.

In accordance with previous studies, the intracellular development of these parasites in the jejunum is rapid thus resulting in fecal output of Eimeria oocysts [14]. Epithelial 


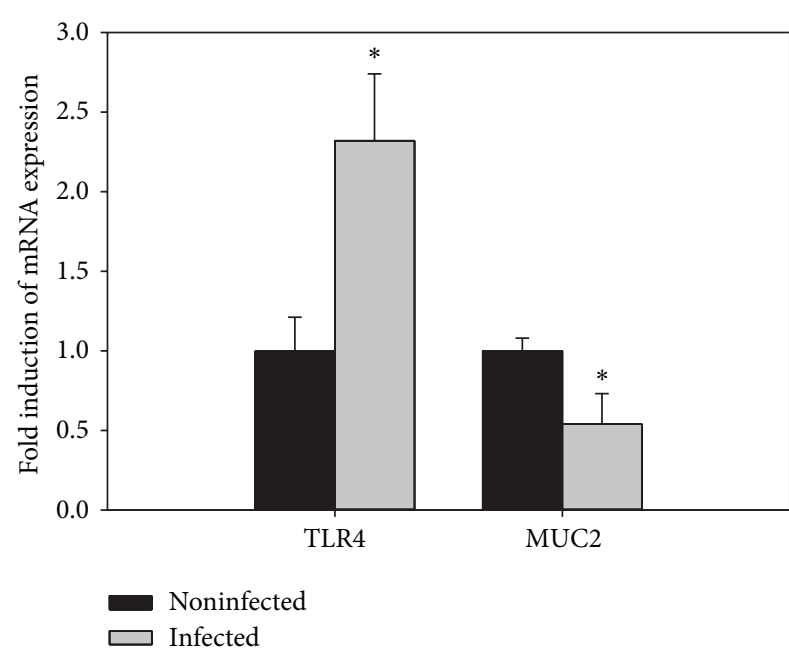

FIGURE 5: Quantitative RT-PCR analysis of TLR4 and MUC2 in the jejunum. Expression was analyzed in non-infected and infected mice on day 5 p.i., normalized to 18S rRNA signals, and relative expression is given as fold increase compared to the non-infected control mice. Values are means $\pm \mathrm{SD}$. ${ }^{*}$ Significant change at $P<0.01$ with respect to noninfected mice.

host cells finally disrupt upon discharging the oocysts, and tissue inflammation is therefore expected to occur during E. papillata infections. Also, our data have revealed that the inflammatory process occurring in mice gut is strong and is exacerbated by protozoal invasion. This is not only recorded by histology but also evidenced by the upregulation of the inflammatory cytokines: TNF- $\alpha$, iNOS, IFN- $\gamma$, and IL- $1 \beta$.

Only IFN- $\alpha$, which is known to activate intracellular cytotoxicity [15], is strongly increased during the infection suggesting a specific role of IFN- $\alpha$ in E. papillata infection. Indeed, previous findings have also shown an increased production of IFN- $\alpha$, mainly by NK-cells, during primary infections with E. papillata [14]. Also, a strong IFN- $\alpha$ response has been described to occur in the intestine upon infection with E. maxima [16], E. bovis, and E. alabamensis [17]. It has been suggested that IFN- $\alpha$ limits the output of oocysts during primary infection with E. papillata [14]. Also, the changes in goblet cell numbers may affect the susceptibility of the parasite-infected host to limit the capacity of opportunistic pathogen from increasing or penetrating the local epithelium [18].

Apoptosis is normal part of development and tissue homeostasis [19]. Apoptotic cells are present in the intestinal crypts and regulate the total amount of progenitor stem cells [20]. The great increase in the amount of apoptosis within E. papillata infected villi may be due to the complex hostparasite interaction. Moreover, apoptosis is an important regulator of the host's response during various intracellular protozoan infections and helps eliminate damaged or infected cells [21].

Our results of qRT-PCR revealed that the expression of MUC-2 is significantly reduced, whereas the expression of MUC-4 is not changed. MUC-2 is the first line of innate host defense in preventing pathogen-induced epithelial injury.
In the absence of MUC-2, mice are more susceptible to Entamoeba histolytica-induced secretory and proinflammatory responses [22]. Moreover, MUC2 ${ }^{-/-}$mice spontaneously develop colitis, indicating that MUC2 is essential for the protection of the colon [23]. The inhibition of the goblet cell marker MUC-2 correlates with an activation of the toll-like receptor 4 (TLR4) (Figure 5). Recently, it was shown that intestinal epithelial TLR4 regulates goblet cell development [24]. In our study, E. papillata induced an upregulation of TLR4 and a downregulation of MUC2 which is consistent with the previous observation. Moreover, E. papillata induces an upregulation of the four miRNA species: miR-1959, MCMV-miR-M23-1-5P, miR-203, and miR-21 [25]. Unfortunately, in silico analysis using the miRWalk database [26] revealed that none of our deregulated genes are a validated target of the described miRNAs.

Collectively, our data suggest that infections of mice with E. papillata not only induce pathogenesis in the jejunum, the final target site of E. papillata, but also induced an upregulation of TLR4 and a downregulation of MUC2. Further studies are required to know the mechanism of goblet cells regulated genes during infection with E. papillata.

\section{Acknowledgment}

The authors extend appreciations to the Deanship of Scientific Research at King Saud University for funding the work through the Research Group Project no. RGP-VPP-198.

\section{References}

[1] V. Liévin-Le Moal and A. L. Servin, "The front line of enteric host defense against unwelcome intrusion of harmful microorganisms: mucins, antimicrobial peptides, and microbiota," Clinical Microbiology Reviews, vol. 19, no. 2, pp. 315-337, 2006.

[2] Y. S. Kim and S. B. Ho, "Intestinal goblet cells and mucins in health and disease: recent insights and progress," Current Gastroenterology Reports, vol. 12, no. 5, pp. 319-330, 2010.

[3] D. Taupin and D. K. Podolsky, "Trefoil factors: initiators of mucosal healing," Nature Reviews Molecular Cell Biology, vol. 4, no. 9, pp. 721-732, 2003.

[4] H. Mehlhorn, Ed., Encyclopedic Reference of Parasitology, vol. 1, Springer, Berlin, Germany, 3rd edition, 2008.

[5] M. A. Dkhil, "Anti-coccidial, anthelmintic and antioxidant activities of Pomegranate (Punica granatum) peel extract," Parasitology Research, vol. 112, no. 7, pp. 2639-2646, 2013.

[6] M. L. Schito, J. R. Barta, and B. Chobotar, "Comparison of four murine Eimeria species in immunocompetent and immunodeficient mice," Journal of Parasitology, vol. 82, no. 2, pp. 255-262, 1996.

[7] Y. E. M. Dommels, C. A. Butts, S. Zhu et al., "Characterization of intestinal inflammation and identification of related gene expression changes in $m d r 1 a^{-/-}$mice," Genes and Nutrition, vol. 2, no. 2, pp. 209-223, 2007.

[8] A. Allen, D. A. Hutton, A. J. Leonard, J. P. Pearson, and L. A. Sellers, "The role of mucus in the protection of the gastroduodenal mucosa," Scandinavian Journal of Gastroenterology, Supplement, vol. 21, no. 125, pp. 71-78, 1986. 
[9] K. J. Livak and T. D. Schmittgen, "Analysis of relative gene expression data using real-time quantitative PCR and the $2^{-\Delta \Delta C_{T}}$ method," Methods, vol. 25, no. 4, pp. 402-408, 2001.

[10] S. Al-Quraishy, D. Delic, H. Sies, F. Wunderlich, A. A. S. AbdelBaki, and M. A. M. Dkhil, "Differential miRNA expression in the mouse jejunum during garlic treatment of Eimeria papillata infections," Parasitology Research, vol. 109, no. 2, pp. 387-394, 2011.

[11] M. A. Dkhil, S. Al-Quraishy, A. E. Abdel Moneim, and D. Delic, "Protective effect of azadirachta indica extract against Eimeria papillata-induced coccidiosis," Parasitology Research, vol. 112, no. 1, pp. 101-106, 2013.

[12] B. Deplancke and H. R. Gaskins, "Microbial modulation of innate defense: goblet cells and the intestinal mucus layer," American Journal of Clinical Nutrition, vol. 73, no. 6, pp. 1131S1141S, 2001.

[13] B. K. Linh, T. Hayashi, and Y. Horii, "Eimeria vermiformis infection reduces goblet cells by multiplication in the crypt cells of the small intestine of $\mathrm{C}_{57} \mathrm{BL} / 6$ mice," Parasitology Research, vol. 104, no. 4, pp. 789-794, 2009.

[14] M. L. Schito and J. R. Barta, "Nonspecific immune responses and mechanisms of resistance to Eimeria papillata infections in mice," Infection and Immunity, vol. 65, no. 8, pp. 3165-3170, 1997.

[15] A. Celada and R. D. Schreiber, "Role of protein kinase C and intracellular calcium mobilization in the induction of macrophage tumoricidal activity by interferon-gamma," Journal of Immunology, vol. 137, no. 7, pp. 2373-2379, 1986.

[16] J. B. W. J. Cornelissen, W. J. C. Swinkels, W. A. Boersma, and J. M. J. Rebel, "Host response to simultaneous infections with Eimeria acervulina, maxima and tenella: a cumulation of single responses," Veterinary Parasitology, vol. 162, no. 1-2, pp. 58-66, 2009.

[17] Y. Alcala-Canto and F. Ibarra-Velarde, "Cytokine gene expression and $\mathrm{NF}_{-K} \mathrm{~B}$ activation following infection of intestinal epithelial cells with Eimeria bovis or Eimeria alabamensis in vitro," Parasite Immunology, vol. 30, no. 3, pp. 175-179, 2008.

[18] M. Yunus, Y. Horii, S. Makimura, and A. L. Smith, "Murine goblet cell hypoplasia during Eimeria pragensis infection is ameliorated by clindamycin treatment," Journal of Veterinary Medical Science, vol. 67, no. 3, pp. 311-315, 2005.

[19] D. L. Vaux and A. Strasser, "The molecular biology of apoptosis," Proceedings of the National Academy of Sciences of the United States of America, vol. 93, no. 6, pp. 2239-2244, 1996.

[20] C. S. Potten, "Epithelial cell growth and differentiation II. intestinal apoptosis," American Journal of Physiology, vol. 273, no. 2, pp. G253-G257, 1997.

[21] C. G. K. Lüder, U. Gross, and M. F. Lopes, "Intracellular protozoan parasites and apoptosis: diverse strategies to modulate parasite-host interactions," Trends in Parasitology, vol. 17, no. 10, pp. 480-486, 2001.

[22] V. Kissoon-Singh, F. Moreau, E. Trusevish, and K. Chadee, "Entamoeba histolytica histolytica exacerbates epithelial tight junction permeability and proinflammatory responses in $\mathrm{Muc2}^{-1-}$ mice," American Journal of Pathology, vol. 182, no. 3, pp. 852-865, 2013.

[23] M. Van der Sluis, B. A. E. De Koning, A. C. J. M. De Bruijn et al., "Muc2-deficient mice spontaneously develop colitis, indicating that MUC2 is critical for colonic protection," Gastroenterology, vol. 131, no. 1, pp. 117-129, 2006.

[24] C. P. Sodhi, M. D. Neal, R. Siggers et al., "Intestinal epithelial toll-like receptor 4 regulates goblet cell development and is required for necrotizing enterocolitis in mice," Gastoenterology, vol. 143, no. 3, pp. 708-718, 2012.

[25] M. Dkhil, A. A. Abdel-Baki, D. Delić, F. Wunderlich, H. Sies, and S. Al-Quraishy, "Eimeria papillata: upregulation of specific miRNA-species in the mouse jejunum," Experimental Parasitology, vol. 127, no. 2, pp. 581-586, 2011.

[26] H. Dweep, C. Sticht, P. Pandey, and N. Gretz, "MiRWalkdatabase: prediction of possible miRNA binding sites by "walking" the genes of three genomes," Journal of Biomedical Informatics, vol. 44, no. 5, pp. 839-847, 2011. 

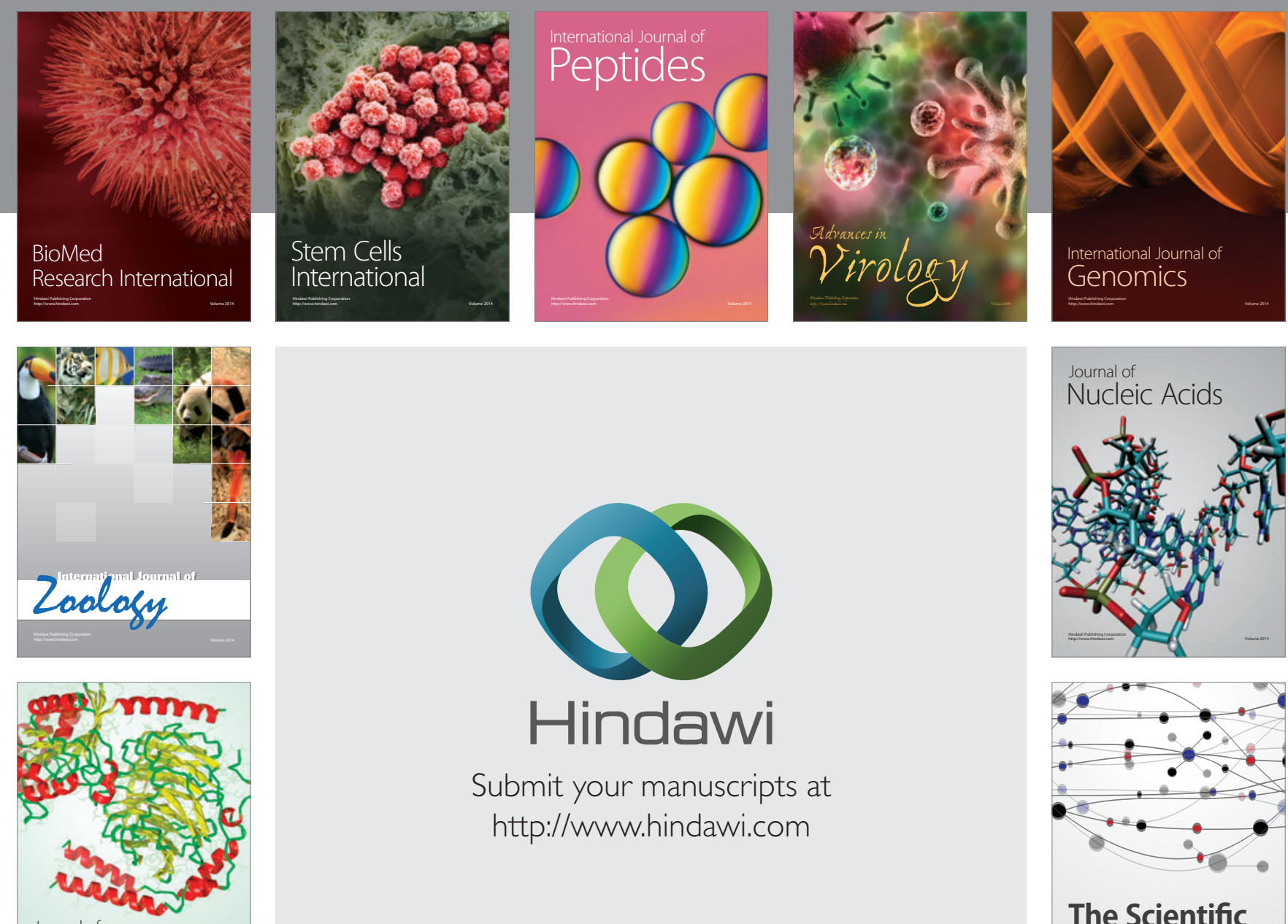

Submit your manuscripts at

http://www.hindawi.com

Journal of
Signal Transduction
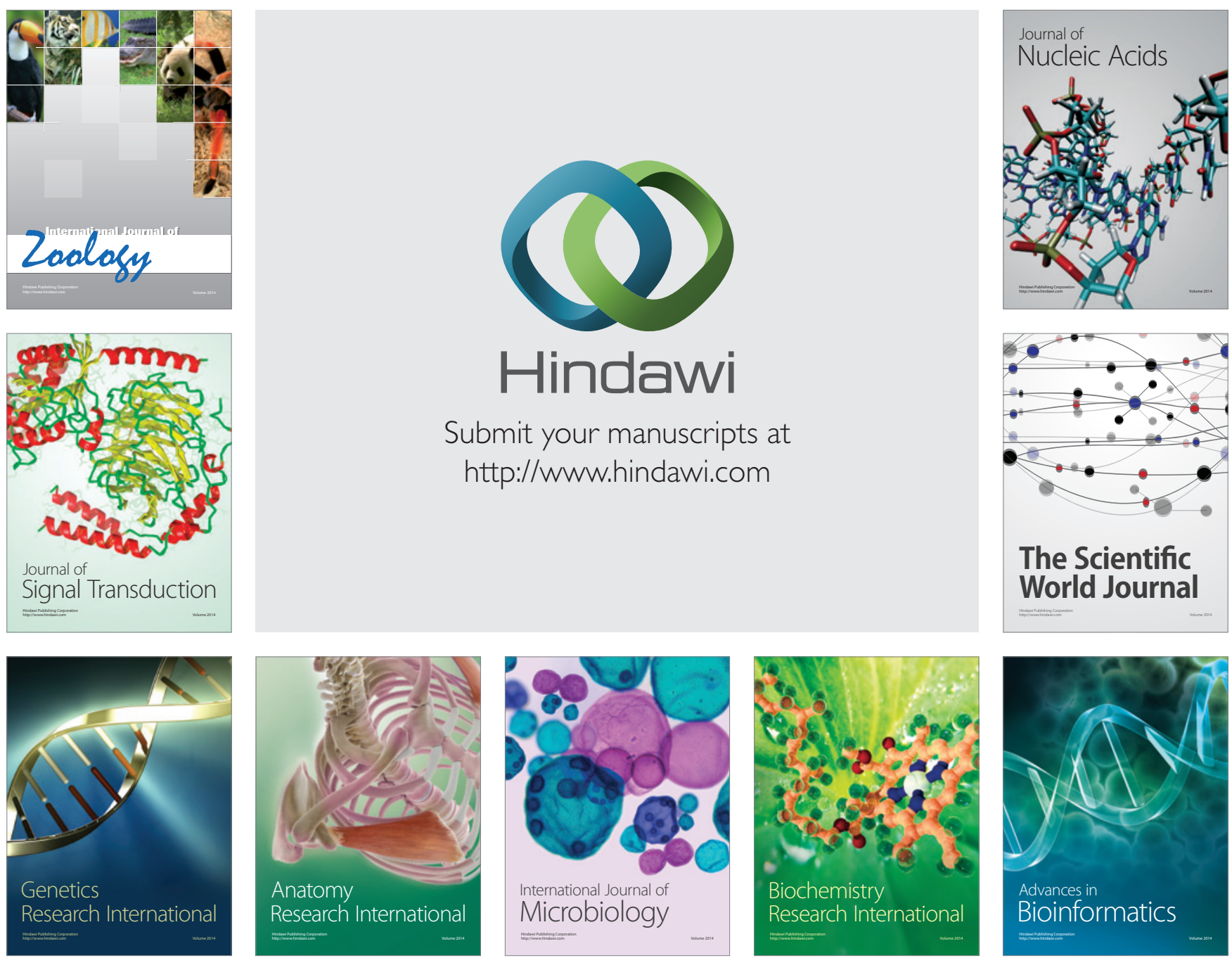

The Scientific World Journal
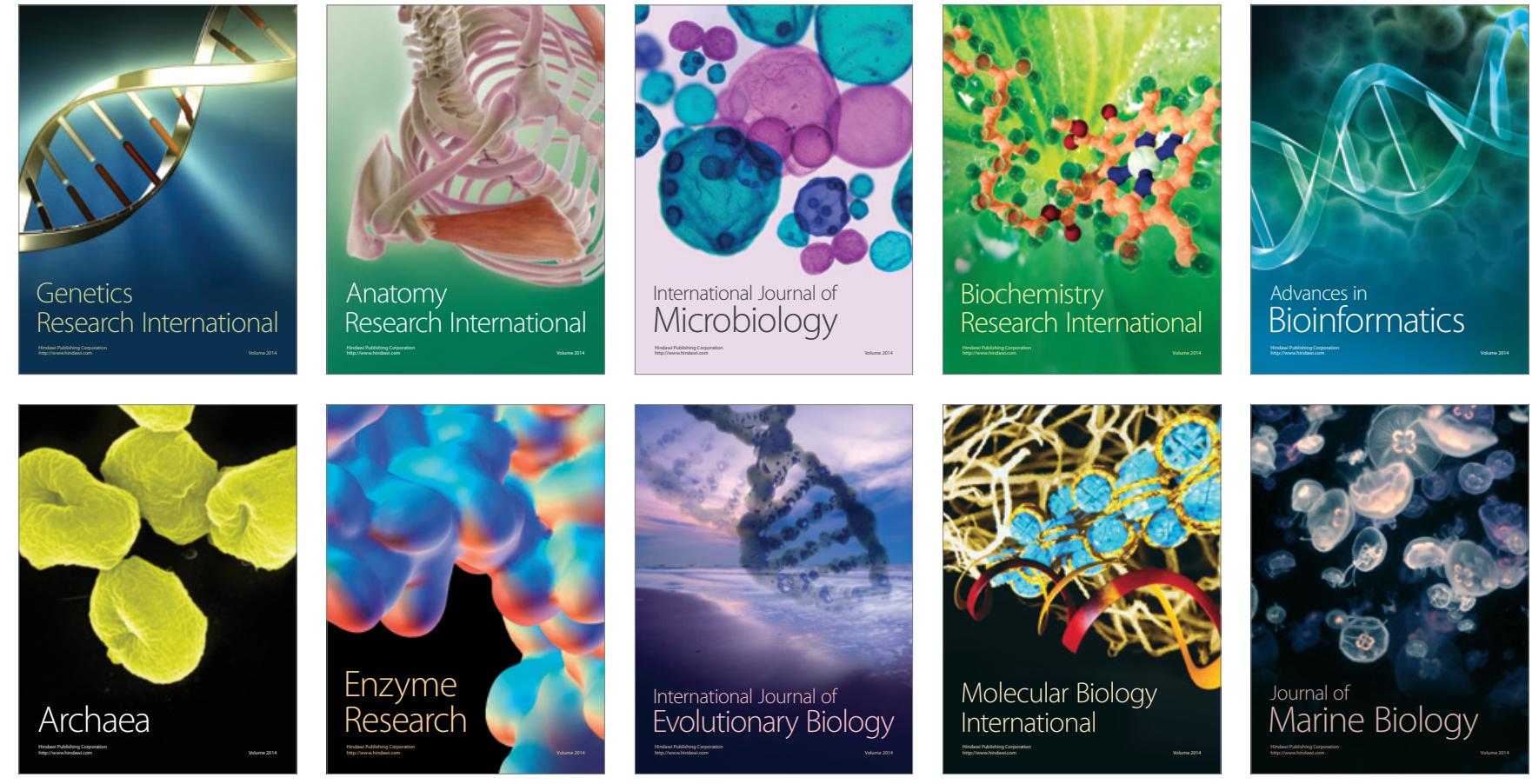